\title{
EL REGLAMENTO DE DESPACHO Y PROCEDIMIENTO ADMINISTRATIVO DEL MINISTERIO DEL EJERCITO*
}

35.077.3

por

Herminio Núñez Maroto

Secretario de primera categoría de Administración local

SUMARIO: I. INTRODUCCION.-II. EL CONCEPTO DE EXPEDIENTE ADMINISTRATIVO.-III. PRESENTACION Y REGISTRO DE DOCUMENTOS.-IV. EL PROCESO DEL TRABAJO ADMINISTRATIVO EN EL PROCEDIMIENTO.-V. INFORMES.

\section{INTR()DUCCION}

Por Orden de 7 de enero de 1975 se aprueba el Reglamento de Despacho y Procedimiento administrativo del Ministerio del Ejército que se presta a un intento de comentario, tanto por la importancia que objetivamente tiene la materia sobre la que versa, como por el hecho de la amplitud de aplicación de sus normas, puesto que cualquier administrado, excepto el militar en asuntos de servicio, ha de acomodarse a sus prescripciones en los procedimientos tramitados por dicho Ministerio.

En ratención «al peculiar carácter y estructura» de los Departamentos militares, según expresa la disposición final segunda de la L.P.A., se adaptó a los mismos dicha Ley por Decreto de 2 de junio de 1966. La doctrina (1) había entendido, con buen criterio,

* Abreviaturas que se utilizan:

C. A. J.: Revista El Consultor de los Ayuntamientos y de los Juzgados.

D. A.: Revista de Documentación Administrativa.

D. A.D. M.: Decreto de adaptación de la Ley de Procedimiento administrativo a los Departamentos militares, de 2 de junio de 1966.

L. P. A.: Ley de Procedimiento administrativo de 17 de julio de 1958, revisada por Ley de 2 de diciembre de 1963.

R.D.P.M. E.: Reglamento de Despacho y Procedimiento administrativo del Ministerio del Ejército, de 7 de enero de 1975.

R. O.F.: Reglamento de Organización, Funcionamiento y Régimen jurídico de las Corporaciones locales, aprobado por Decreto de 17 de mayo de 1952.

(1) CRESPO MONTES: «La Ley de Procedimiento administrativo y su aplicación en la Administración militarn, en $D$. A., número 51, páginas 16 y 17. También GonzAlez NAVARR0: “Estudio preliminar», en Procedimientos administrativos especiales, volumen I, Madrid, 1967, página 20. 
que tal adaptación debía hacerse tomando como base los preceptos de la L.P.A. y recogiendo las particularidades que presentara la materia. El examen del mencionado Decreto demuestra que el parecer doctrinal apuntado ha prevalecido, por lo que, tal vez, hubiera sido suficiente declarar aplicable a los Departamentos militares la L.P. A. directamente, salvo supuestos a determinar casuísticamente, ejemplos de los cuales pueden ser, entre otros, los contemplados en los artículos 25.3, 26, in finem, y 66.5 del mismo.

Puesto que con el repetido Decreto se pretendía una labor de mera adaptación, entendida ésta, además, en el sentido expuesto, no se aprecia en él perfeccionamiento alguno con respecto a la L. P. A. En cambio, el Reglamento objeto de estas consideraciones sí acusa, a su adecuado nivel, algunos aspectos laudables. Por de pronto, estamos ante un único texto reglamentario (aunque tenga que existir uno por cada Ministerio militar), frente a la dispersión que presenta la reglamentación de la L.P.A. De otra parte, se cubre en él una laguna que presenta la L.P.A. y, por tanto, también el D.A.D.M.: la regulación del archivo (2), a la que dedica cuatro preceptos, los artículos 65 a 68, de valioso contenido y que constituyen buen punto de partida para una ulterior normación de tipo interno. Muy interesante es el artículo 73, relativo a la Biblioteca del Ministerio, que «tendrá como misión fundamental el facilitar la consulta de publicaciones que permitan la mejor resolución de asuntos por los distintos órganos del Ministerio». Peculiaridad típicamente castrense presenta el llamado "Servicio del Ministerio», al que el artículo 69-1.1 asigna como misión "resolver las incidencias predominantemente de naturaleza administrativa que se originen fuera de las horas de oficina...».

Frente a los anteriores y otros merecimientos es posible oponer, sin embargo, varios reparos debidos, sin duda, a la nula ambición que implica la aludida finalidad de adaptación del D. A. D. M., impuesta por la disposición final segunda de la L.P.A., aunque también hay defectos, de varia importancia, que no obedecen a dicha causa; así, llama la atención el epígrafe "De las visitas», puesto al capítulo $\mathrm{XV}$, que, en realidad, disciplina únicamente la información de tipo general y particular, ya que las que no tengan esta finalidad se encauzarán de acuerdo a normas a dictar por la Subsecretaría. De ambos aspectos, méritos y reparos, pretendo ocu-

(2) SÁNCHEZ Belda: aUn lapsus en la Ley de Procedimiento administrativo» (sobre archivos), en $D$. A., números 62-63. 
parme seguidamente; pero no con relación a todo el R.D.P.M. E., sino sólo respecto a los temas que enuncian los epígrafes siguientes y, aun así, limitándome a los aspectos más relevantes o de personal preferencia.

Un último comentario previo ha de referirse, inexcusablemente, a la no publicación de este Reglamento en el Boletín Oficial del Estado, lo que está en contradicción con su propio artículo $41.1, b$ ), y lleva consigo la no producción de efectos jurídicos de carácter general, desplegando su eficacia únicamente intra muros del Ministerio. Ello es lamentable sobre todo en cuanto al aspecto estrictamente procedimental, como se tendrá ocasión de comprobar al glosar su artículo 52 en el apartado III de estas consideraciones.

Publicado este Reglamento en el Diario Oficial del Ministerio del Ejército y no disponiendo del correspondiente ejemplar, ha de advertirse que se ha tenido a la vista el texto recogido en la colección legislativa Aranzadi.

\section{EL CONCEPTO DE EXPEDIENTE ADMINISTRATIVO}

Continuando la tradición de textos reglamentarios de otras épocas (3), trata de definir el R.D.P.M.E. lo que sea el expediente administrativo en su artículo 33. A pesar del riesgo que comporta, tal intento puede ser plausible habida cuenta de que, como en otro lugar he puesto de relieve (4), tanto por la legislación como por la doctrina se utilizan frecuentemente con imprecisión, y a veces como sinónimos, los términos procedimiento y expediente, si bien esta confusión terminológica no autoriza siempre a suponer confusión conceptual en quienes así proceden. También cabe invocar las siguientes palabras preliminares del R.D.P.M.E.: «Se define el expediente administrativo, cuyo concepto es necesario el ( sic) conocer, habida cuenta de las consecuencias jurídicas de los defectos de forma que puedan producirse en el curso de un procedimiento, y de los que el expediente es medio de constatación".

Ahora bien, si en base a las anteriores $u$ otras razones, se decide definir el expediente administrativo, ello hay que hacerlo precisando su verdadera naturaleza a través de las notas que configu-

(3) Reglamento de Procedimiento del Ministerio de la Gobernación, artículo 46. Reglamento de Procedimiento administrativo jel Ministerio de Industria, artículo 32.

(4) Vid. mi trabajo: "Sobre el concepto de expediente», en C. A. J., número 12 de 1972, páginas 716 a 718 . 
ran su concepto, en una fórmula válida y actual. Esto es, precisamente, lo que no hace el R.D.P.M.E., que se limita a seguir al R. O. F. mediante una transcripción casi literal (5), siquiera acuse, con respecto a este último texto, algún leve perfeccionamiento.

Para demostrar la anterior afirmación, me será disculpado reproducir sucesivamente los tres párrafos de que consta el artículo 33 del R. D.P.M. E. Dice el apartado 1 del citado precepto que «el procedimiento podrá iniciarse de oficio o a instancia de persona interesada, incoándose el oportuno expediente». La primera parte de este párrafo es algo elemental y mera reproducción del artículo 67 de la L.P.A. y del D.A.D. M.; pero supera la confusión del artículo 279 del R. O.F. que refiere, equivocadamente, a los expedientes, y no al procedimiento, las dos modalidades transcritas de la iniciación de oficio y a instancia de parte. La último expresión de este apartado, «incoándose el oportuno expediente», puede considerarse un acierto porque, como luego veremos, la formación de un expediente depende de que nazca un procedimiento, aunque aquél puede incluir también documentos referentes a actuaciones que no formen parte de tal procedimiento.

El primer párrafo del apartado 2 del precepto que comentamos dice que "constituye expediente el conjunto ordenado y numerado de documentos y actuaciones que sirven de antecedente y fundamento a la resolución administrativa, así como las diligencias encaminadas a ejecutarla», con lo cual se reproduce enteramente el número 1 del artículo 278 del R. O.F. al que se añaden únicamente las palabras "y numerado». Estamos ante una modificación banal, que se refiere a un dato o requisito ínsito en la exigencia que implican los anteriores vocablos "conjunto ordenado" y que no puede sustituir con ventaja la garantía del requisito, previsto en el número 2 del artículo 278 del R. O. F., de que las hojas útiles del expediente «serán rubricadas $\mathrm{y}$ foliadas por los funcionarios encar-

(5) Conviene recordar que el artículo 278 del R. O.F. dice: «1. Constituye expediente el conjunto ordenado de documentos y actuaciones que sirven de antecedentes y fundamento a la resolución administrativa, así como las diligencias encaminadas a ejecutarla. 2. Los expedientes se formarán mediante la agregación sucesiva de cuantos documentos, pruebas, dictámenes, decretos, acuerdos, notificaciones y demás diligencias deban integrarlos y sus hojas útiles serán rubricadas y foliadas por los funcionarios encargados de su tramitaciónn. El siguiente artículo 279 dice: aLos expedientes se iniciarán: a) de oficio, cuando se trate de necesidades del servicio público o de exigir responsabilidades a los miembros o funcionarios de las Corporaciones locales; y $b$ ) a instancia de parte, cuando se promuevan para resolver pretensiones deducidas por los particulares. Será cabeza del expediente en los primeros el acuerdo u orden de proceder, y en los segundos la petición o solicitud decretada para su trámites. 
gados de su tramitación». El precepto adolece del mismo defecto fundamental que el R.O.F., pues, aparte de otras posibles objeciones, no abarca la expresión documental de la resolución, sino de lo anterior y de lo posterior a la misma, y hace referencia a «actuaciones», cuando sólo debe hacerlo al reflejo documental de las mismas (6).

El segundo párrafo del apartado 2 del artículo 33 que comentamos expresa que «los expedientes se formarán mediante la agregación sucesiva de cuantos documentos, pruebas, informes, acuerdos y demás diligencias que deban integrarlos. Será cabeza del expediente la orden o acuerdo de proceder o la instancia o petición del interesado» (7). Lo transcrito es, claramente, una refundición de lo dispuesto en los artículos 278.2 y 279 , último párrafo, del R. O.F., en los cuales se ha acortado la enumeración de diligencias y se ha suprimido el requisito de que la instancia o petición del interesado esté "decretada para su trámite».

Aunque, como antes se prometió, más adelante será precisado, séanos permitido anticipar que en los procedimientos iniciados de oficio, la «orden o acuerdo de proceder» marca justamente el momento inicial del procedimiento (8); pero el primer documento del expediente relativo a dichos procedimientos puede ser, no aquel en que se recoja tal orden o acuerdo, sino aquel otro en que se contenga la moción, sugerencia o denuncia presentada por los subordinados o los administrados. En cambio, en los procedimientos iniciados a instancia de parte, la solicitud del particular presentada al órgano administrativo marca el comienzo del procedimiento (9) y, además, constituye el primer documento integrador del expediente, por lo que ha de considerarse un acierto la supresión de la frase "decretada para su trámite», que parece indicar la necesidad de un decreto o acuerdo administrativo para que el procedimiento surja.

(6) Sobre estos extremos y para todo lo que sigue en el texto, vid. mi trabajo: "Sobre el concepto de expediente", aludido en la nota (4).

(7) $\mathrm{Al}$ decir en el texto «o la instancia o petición del interesados, se salva el error tipográfico del precepto consignado arriba, que dice: "a la instancia o petición del interesado».

(8) $\mathrm{Si}$, con arreglo al artículo 65.1. in finem de la L. P. A. y del D. A. D. M., se hiciesen registrar el acuerdo u orden de proceder, ello implicaría una operación interesante a efectos del debido control de la tramitación de los procedimientos iniciados de oficio, control para el cual el Registro, bien concebido y llevado, es un instrumento insuperable; pero no afecta a la existencia del procedimiento iniciado de oficio con anterioridad a dicha operación de registro, que debería ser obligatoria y no facultativa, salvo en supuestos muy especiales.

(9) Vid. mi libro: Iniciación y desarrollo del procedimiento administrativo municipal ordinario, Villanueva de los Infantes (Ciudad Real), 1973, páginas 52 y 53. 
Expuesto lo anterior, se hace necesario precisar las notas que configuran el concepto de expediente, que, a mi juicio, son éstas:

1. ${ }^{a} \quad$ La literalidad o materialización documental. En esto coincide la doctrina haciendo precisiones verdaderas (10), pero incompletas por cuanto a esta nota debe inmediatamente añadirse la siguiente.

2. ${ }^{\mathrm{a}}$ Totalidad, en el sentido de que el expediente abarca desde el primer documento relativo a un asunto, aunque la actuación que incorpore no se integre en el procedimiento, hasta la última diligencia consignada por escrito expresiva de su completa y total ejecución (11). En virtud de exigencia, es claro que deben integrarse en el expediente, como ya hemos adelantado, los documentos en que se contengan las mociones, sugerencias o denuncias, cuando, en base a ellas, decide la Administración iniciar de oficio el procedimiento, pues, en estos supuestos, tales mociones, sugerencias o denuncias son un «antecedente» de la resolución que se dicte, tanto que, tal vez, sin ellas no hubiera la Administración caído en la cuenta de la necesidad o conveniencia de tramitar el procedimiento. En cambio, las aludidas modalidades de colaboración, ya sean espontáneas $\mathrm{u}$ obligadas, no forman parte del procedimiento que es el que se inicia en verdad, y no el expediente, con «el acuerdo u orden

(10) Rovira Mola, en la voz aExpediente», en la Nueva Enciclopedia Jurídica Seix, página 251, dice que el expediente es ala documentación de las actuaciones y diligencias del procedimiento administrativon. EnTrena CuEsta: Curso de Derecho Administrativo, Madrid, 1968, afirma que ael procedimiento administrativo no debe confundirse con el expediente administrativo, que representa su materializaciónn. Guarta: La revisión de la Ley de Procedimiento administrativo, Madrid, 1964, página 30, afirma: aEl expediente no es otra cosa que la materialización de aquél, el procedimiento hecho papel». Las palabras preliminares del R.D.P.M.E. dicen que ael expediente es medio de constatación». GonzAlEz NAvarro afirma que ael expediente es el resultado que se obtiene de la llamada actividad de constancian. Vid. la obra de este autor: El procedimiento administrativo en la doctrina cientifica, Madrid, 1972, página 23, con referencia a su trabajo, citado en nota (13) de dicha página: «Procedimiento administrativo y vía administrativa».

(11) Esta nota de totalidad la refleja Rovira Mola, en el trabajo citado en nota anterior, página 250, al proporcionar también el siguiente concepto de expediente: aConjunto de actuaciones constitutivas de un asunto o negocion. Gallego BurfN: Derecho secretarial de Administración local, tomo II, Madrid, 1948, página 185, afirma: aEn términos burocráticos todo asunto tramitado se traduce en un expediente». La idea de totalidad también está presente en la afirmación, contenida en la sentencia de 7 de julio de 1962, de que ano puede ordenarse el archivo de un expediente que no esté terminado en su trámite y ejecución». E, igualmente, el propio significado gramatical abona esta nota, ya que, según el Diccionario de la Real Academia de la Lengua, expediente es el aconjunto de todos los papeles correspondientes a un asunto o negocio» o el aconjunto de documentos relativos a un asunto». Estos conceptos son sumamente exactos, pues, aparte del término aconjunto», que se ha querido ahora resaltar, las palabras apapeles» y adocumentos» resaltan la anterior nota de literalidad o materialización documental. 
de proceder», aparte de que tampoco tienen, a diferencia de la instancia del particular, virtualidad suficiente para provocarle, pues la apreciación de las necesidades públicas corresponde, por definición, a las autoridades y organismos de este carácter (12).

3. $\quad$ La agregación o incorporación sucesiva y ordenada (con el añadido, si se quiere, de su numeración o, mejor, con la de su rubricado y foliado), nota formal y externa que completa las anteriores.

En base a estas notas pudiera resultar aceptable la definición del expediente como expresión o reflejo documental, ordenado y sucesivo, de todos los actos y actuaciones en general, realizadas para la completa tramitación de algún asunto de competencia administrativa. Definición que tiene la suficiente amplitud para no prejuzgar la diversa naturaleza de lo documentado en el expediente.

La importancia en la precisión del concepto de expediente no es sólo de índole teórica, sino también eminentemente práctica. A medida que el expediente se va formando, se va haciendo también la historia del asunto a que se refiera, la cual ha de ser tenida muy en cuenta por el órgano llamado a dictar resolución, toda vez que constituye el "antecedente y fundamento de la misma». La interposición del recurso de alzada, ya se presente el recurso ante el superior jerárquico, ya ante el propio órgano que dictó el acto impugnado, origina la inmediata necesidad de que éste remita a aquél el expediente (artículo 123 de la L. P. A.) (13). Igualmente, a tenor del artículo 61 de la Ley reguladora de la Jurisdicción contenciosoadministrativa, el Tribunal, en el día siguiente hábil a la interposición del recurso de esta índole, acordará reclamar el expediente administrativo a la Administración autora del acto o disposición. El expediente se convierte así en elemento clave e imprescindible del que no se puede ni debe excluir ningún documento integrante del mismo, pues aun las simples sugerencias, denuncias o mociones pueden suministrar al órgano decisor o revisor algún motivo interesante de interpretación.

(12) La sentencia de 30 de marzo de 1967 dice que aen la apreciación de si el acto a realizar redunda en beneficio de sus bienes o derechos, hay que conceder a la Corporación un margen de discrecionalidadn.

La sentencia de 30 de noviembre de 1957 afirma, de otra parte, que la iniciación de oficio indica que no es preciso tramitar ningún expediente previo. Pero de tal sentencia se deduce, a sensu contrario, que, en otras ocasiones, sí puede haber expediente previo, es decir, actuaciones, debidamente documentadas, obligadas o espontáneas, que induzcan con posterioridad a la Administración a dictar el inicial acto de trámite del procedimiento.

(13) GONZALEZ PÉREZ: Los recursos administrativos, Madrid, 1969, página 274. 
Particular aplicación de cuanto se deja expuesto hace la L. P. A. y, obviamente, también el D.A.D.M., al regular el procedimiento para la elaboración de disposiciones de carácter general. El artículo 129.2 de ambas disposiciones ordena conservar expresamente, junto a otros datos y antecedentes, las mociones presentadas por los subordinados. Como González Pérez hace notar (14), este procedimiento "únicamente puede incoarse de oficio, dada su naturaleza especial»y, por ello, el artículo 129.1 de las disposiciones de referencia dice que «se iniciará por el Centro directivo correspondiente»; pero, aplicando el precepto general contenido en el artículo 68 de la L. P. A., concluye el autor citado (15) que, «en consecuencia, se incoará por acuerdo del órgano competente, bien por propia iniciativa o como consecuencia de orden superior o de moción razonada de los subordinados» y añade (16) que "en estos últimos supuestos, la orden del superior o la moción del inferior no constituyen el acto de incoación; el procedimiento no quedará incoado hasta que por el órgano competente se adopte el acuerdo correspondiente». Sin embargo, dicha orden y, en particular, dicha moción, que no forman parte del procedimiento, sí deben conservarse porque el documento en que se contienen integra el oportuno expediente.

A pesar de lo dicho anteriormente no queda excluida en este procedimiento de elaboración de disposiciones de carácter general la colaboración de los administrados. En efecto, la Ley de 22 de diciembre de 1960, reguladora del llamado derecho de petición, dispone en su artículo $\mathbf{1 1 . 2}$ que, si la petición fuese fundada y las medidas a adoptar exigen dictar una disposición general, se incoará el procedimiento correspondiente, según la jerarquía de la disposición. Pues bien, en este supuesto tal petición, surgida como consecuencia del ejercicio de ese singular derecho, no forma parte del procedimiento en cuestión, pero sí debe conservarse como integrante del expediente, pues, al decir de Desantes GuANTER (17), «la enumeración de documentos que la Ley (se refiere al artículo 129.2 de la L.P.A.) hace no pretende ser exhaustiva, ya que se entiende que todo lo que ha servido de base, lo que ha contribuido en cualquier forma, tanto positiva como negativamente, a la formulación

(14) González Pérez: El procedimiento administrativo, Madrid, 1964, página 609.

(15) González Pérez: El procedimiento..., cit., página 609.

(16) GonzÁlez Pérez: El procedimiento..., cit., página 610.

(17) Desantes GunTER: «La elaboración de disposiciones generales en la L.P. A.», citado por GONZALEZ NAVARRo en El procedimiento administrativo, cit., página 703. 
de la disposición general de que se trate, debe ser conservado, formando un expediente (el subrayado es mío) que, lógicamente, terminará con la norma tal como esté destinada a su publicación». Y, añade el citado autor (18), «la previsión de la Ley es en este caso también acertada. Los materiales que manda conservar pueden ser de gran utilidad... como material para poder disipar en cualquier caso dudas de interpretación o abrir posibilidades nuevas de interpretación o, lo que es lo mismo, de eficacia de las normas».

En resumen, el expediente no es sólo la documentación del procedimiento administrativo; incluye también la de otras actuaciones posibles cuyo conocimiento puede ser importante a la hora de dictar los actos o de revisar los mismos, según ha quedado resenado. $Y$ es de notar que los supuestos de derecho positivo aducidos podrían multiplicarse.

\section{PRESENTACION Y REGISTRO DE DOCUMENTOS}

Antes de examinar las cuestiones que juzgo más interesantes entre las que plantean las disposiciones del R. D. P. M. E. sobre la materia que enuncia el precedente epígrafe, me parece oportuno precisar previamente que:

1. Aunque puede estimarse acertado el criterio de la L.P.A. y del D.A. D. M., que disćiplinan la presentación y registro de documentos con anterioridad inmediata (capítulo $\mathrm{V}$ y último de su título III) a la regulación del procedimiento (título IV), por la utilidad que implica el conocimiento previo de la primera temática enunciada respecto de la segunda, también cabe, en una cierta ordenación expositiva, la consideración de la presentación y registro como materia a tratar a renglón seguido de la indicación de los modos o formas de iniciación del procedimiento. Sin embargo, el R. D. P.M. E. no sigue ni un criterio ni otro, pues trata "del procedimiento administrativo» en su capítulo $\mathrm{X}$ y «del registro de la correspondencia» en el XII, intercalando entre ambos normas, que integran el capítulo XI, relativas a la publicación de disposiciones y resoluciones, con lo cual, a la vez que muestra una defectuosa sistemática, rompe la necesaria ligazón entre aquellas materias.

2. Como ya se ha anotado, el R. D.P.M. E. utiliza la expresión «registro de la correspondencia», que quiere significar, y significa,

(18) Desantes Guanter: Mismo trabajo de la nota anterior, cit., igualmente, por GONZALEZ NAVARRo en El procedimiento administrativo, páginas 703 y 704. 
registro de entrada de documentos, tanto de los presentados por los propios interesados o sus representantes, como de los que lleguen por correo de procedencia particular u oficial. Ello es así porque el término correspondencia tiene, junto a uno más estricto, un sentido amplio comprensivo de todo lo apuntado, que es el que aparece recogido en su artículo 48. Empero, tal expresión, a pesar del uso generalizado de la misma, debería desecharse porque parece excluir la posibilidad de registrar los "proveídos de oficio que hayan de iniciar el procedimiento cuando así lo acordare la autoridad que los adopte», lo que, evidentemente, no sucede por permitirlo expresamente los artículos 65.1 de la L. P. A. y del D. A. D. M.

3. Las disposiciones últimamente citadas disciplinan únicamente el llamado registro de entradas de documentos; pero no el de su salida. De la misma limitación adolece el R.D.P.M. E., aunque pormenorice respecto de otras materias tales como registros particulares, índices relativos a los asuntos de las secciones y correspondencia interna del Ministerio. Es de lamentar tal limitación, pues podía haberse regulado praeter legem la organización y funcionamiento del registro de salida, cuya importancia es indudable (19), inspirándose en los principios básicos del capítulo I del título III de la L.P.A. y D. A. D. M., en los particulares que informan la regulación del registro de entrada en cuanto fuesen aplicables al de salida y en los derivados de la peculiar función a desempeñar por este último. Es imperdonable que, a todos los niveles normativos, se haya hecho caso omiso del precedente del R. O.F., que sí disciplina el registro de salida en sus artículos 264 y siguientes.

Precisado lo anterior, podemos entrar en el examen de las otras cuestiones $\mathrm{y}$, en primer lugar, de la instancia del particular y sus condiciones. A ello se refiere el artículo 69.1 del D. A. D. M., que es reproducción literal del mismo precepto de la L. P. A., enumerando, por tanto, idénticamente los requisitos que debe reunir dicha instancia (20), con la sola adición, muy lógica, de que «los militares

(19) Carrasco Belinchón, Vizcafno Coloma y Mahfllo Santos: Simplificación administrativa en las Corporaciones locales. I Registro de entrada y salida de documentos. Oficina de información, Madrid, 1967, página 152, dicen: aAmbos Registros son parte esencial de la organización: el de entrada controla la relación del público con la Administración; el de salida fiscaliza la relación de ésta con aquél».

(20) Se mantiene, pues, en el D.A.D.M., el clásico modelo impetratorio y suplicante de instancia cuya abolición se pide por todos. Vid. BLANCo DE TELla: «Reflexiones sobre el lenguaje administrativo», en $D$. A., número 122, página 86. GonzA- 
expresarán también su empleo y destino» (21). Los indicados en este precepto, más el reintegro, aludido en el artículo 71 de ambas disposiciones, son los que, en total, debe reunir la instancia. $\mathrm{Y}$ a su defecto $u$ omisión da el mismo tratamiento el precitado artículo 71: «requerir a quien le hubiese firmado para que, en un plazo de diez días, subsane la falta o acompañe los documentos preceptivos, con apercibimiento de que si así no lo hiciere, se archivará sin más trámites». Ello implica que, aunque sean defectuosos, y aunque el defecto consista en la omisión o insuficiencia del reintegro, los documentos deben registrarse para proceder después como queda indicado.

Sabido es que la Ley de Reforma del Sistema Tributario de 11 de junio de 1964, por su artículo 176.5, derogó, en cuanto al reintegro, el artículo 71 de la L.P. A., disponiendo la obligación de no registrar «sin el pago del impuesto pertinente las instancias o recursos que los particulares presenten". Y también que el artículo 114 del texto refundido de la Ley y Tarifas de los Impuestos Generales sobre las Sucesiones y sobre Transmisiones Patrimoniales y Actos Jurídicos Documentados, aprobado por Decreto de 6 de abril de 1967, vuelve al criterio de la admisión y requerimiento de subsanación de la L. P.A. Ahora bien, el D.A.D.M. es de 2 de junio de 1966, anterior, por tanto, al texto refundido citado y, sin embargo, no tuvo en cuenta para nada la aludida derogación del artículo 71 de la L. P. A., en cuanto al reintegro, transcribiéndole íntegramente. En cambio, el R.D.P.M.E., que es posterior al repetido texto refundido, sí pudo, pero sus redactores no quisieron, transcribir el artículo 71 de la L. P.A. y del D.A. D. M., a pesar de que su transcripción, de acuerdo con las propias palabras de su preámbulo, hubiera resultado muy útil y esclarecedora. En definitiva, no se ha querido examinar de frente el problema de la eficacia del Decreto de 6 de abril de 1967, por el que se aprueba el repetido texto refundido, frente a la Ley de Reforma del Sistema Tributario (22)

LEZ NavarRo: «Modelos de instancia y estilo administrativo», en $D$. $A$., número 121, página 78. NúNÉEZ MaRoto: Iniciación y desarrollo..., cit., páginas 39 y 40 . Un modelo de instancia aconsejable es el que exhibe la revista Certamen en la página 88 de su número 393, de 28 de febrero de 1975.

(21) El artículo 54 del R. D. P. M. E. puntualiza que «toda la correspondencia se dirigirá a mi autoridad (esto es, al Ministro), haciéndose constar el órgano destinatario... Cuando sea posible se indicará también la Sección a que corresponde el asunton.

(22) Sobre el tema, vid. Gonzalez Navarro: «La admisión condicionada de documentos sin reintegro», en $D$. $A$., número 118. También ARroyo GaRcfa: "El reintegro como requisito en los documentos administrativos», en $C$. A.J., número 29 del 
en este particular punto de la omisión o insuficiencia de reintegro. Buena prueba de ello es el artículo 53 de este R. D.P.M. E., cuyo número 1 da por supuesto que todo documento debe presentarse debidamente reintegrado, silenciando lo relativo a la tacha que comporta la omisión o defecto del reintegro y el tratamiento que merezca la misma; por contraposición, su número 2 consigna la obligación de instruir al interesado sobre las demás faltas de que adolezca el escrito que presente a fin de subsanarlas antes de cursarle, si fuera posible; pero si no cabe la subsanación inmediata o si el escrito no se presenta personalmente, se «enviará, sin embargo, a la Sección que corresponda despachar el asunto, quien proveerá». Lo único que cabe proveer es, claro está, el requerimiento para que, en el plazo de diez días, se subsane la falta. Y no cabe duda respecto a que estas dos últimas previsiones debieron ser extendidas al supuesto del defecto u omisión del reintegro, aunque, pienso, así se procederá en la práctica, pues tal tacha es, a mi juicio, la de menor importancia de todas las que puedan afectar a la instancia.

Teóricamente cabe, por otra parte, que no sea la Sección correspondiente quien haga ese requerimiento, sino el propio encargado del Registro de entrada, el cual, después de transcurridos los diez días de plazo legal, enviaría el escrito defectuoso al archivo si las tachas de que adoleciese el mismo no se hubiesen subsanado en dicho plazo, o a la Sección correspondiente, para su debida tramitación, si, por el contrario, el particular hubiese atendido el requerimiento; pero, en este caso, acto seguido a la subsanación sin retener para nada la instancia. Ello, sin embargo, no es posible porque el artículo 65.3 del D.A.D.M. no ha previsto, como tampoco la L.P.A., una casilla para anotar las observaciones necesarias, a diferencia del R.O.F. (23), que ha sido más previsor a este respecto, ni el R.D.P.M.E. asigna estas funciones al encargado del Registro, como se deduce del anteriormente comentado número 2 de su artículo 53.

De muy distinta manera a cuanto ha quedado expuesto a propósito del reintegro procede el R.D.P.M. E. con respecto al problema de la presentación de escritos. El artículo 52 de este Regla-

año 1969. Puede ser también objeto de estudio el problema del reintegro no sólo con referencia a las instancias y recursos y sus documentos acompañantes, sino también con respecto a los documentos que se incorporen a un procedimiento ya en tramitación. Vid., sobre este particular y con referencia a las certificaciones, mi trabajo "Certificaciones é informes. Diverso tratamiento fiscal», en $C$. A.J., número 29 del año 1970.

(23) Vid. su artículo 266. 
mento dispone que «los escritos que promuevan el personal no militar y el militar en asuntos ajenos al servicio, podrán presentarse en el Registro General o en cualquiera de las Dependencias referidas en la legislación de procedimiento administrativo". Los militares no tienen, respecto de los asuntos relativos al servicio, esta opción, sino que necesariamente han de utilizar la vía reglamentaria establecida para ello (vid. artículos 66.5 del D. A. D. M. y 51 del R. D.P.M. E.). Por lo demás, «la legislación de procedimiento administrativo" no puede, en principio, ser otra que el D.A.D.M., en su artículo 66, a cuyo tenor y al del anterior artículo 65, los escritos dirigidos al Ministerio del Ejército pueden presentarse en:

- El Registro General del Ministerio.

- La dependencia más caracterizada que del Ministerio del Ejército exista en cada localidad (24).

- Las oficinas de correos que, al menos, tengan categoría de estafetas (25).

- Las representaciones consulares y diplomáticas españolas por parte de los españoles que se encuentren en el extranjero.

Fácilmente se observa en esta enumeración las mayores posibilidades que ofrece a los administrados el artículo 66 de la L. P. A. al permitir la presentación de escritos en los Gobiernos civiles, dado el carácter de estos centros, con destino «a cualquier órgano de la Administración civil del Estado que radique en la propia o en distinta Provincian.

Lo verdaderamente interesante, sobre lo que quería llamar la atención, es que el artículo 52 del R. D. P. M. E. se completa disponiendo: «las cuales (es decir, las aludidas dependencias) los admitirán (los escritos), dando recibo a los interesados, si lo solicitan, sirviendo como tal una fotocopia o copia simple del escrito o documento de que se trate, fechada o sellada por el funcionario a quien se entrega». Esto, en cuanto entre tales dependencias están las oficinas de correos que tengan, al menos, categoría de estafetas, supone una decidida y acertada interpretación de la legislación su-

(24) González NAVARro: «Vías indirectas de presentación de escritos y documentos administrativos», en $D$. $A$., número 119 , páginas $43-44$, señala acertadamente la imprecisión de que adolecen las expresiones "órganos delegados de los distintos Ministerios», que utiliza el artículo 66.2 de la L.P.A., y "dependencia más caracterizada de cada uno de los Ministerios militares», que usa el D.A.D.M. en su artículo 66.1.

(25) La categoría de estafeta viene exigido por el artículo 1.1 de la Orden de 20 de octubre de 1958. 
perior al respecto. Tanto la L. P. A. como el D. A. D. M., ambos en su artículo 69.2, refieren la obligación de dar recibo, en cualquiera de las modalidades aludidas, a todas «las oficinas de la Administración", sin que quepa excluir, por tanto, a las oficinas de correos. Así lo entendió la Orden de la Presidencia del Gobierno de 22 de octubre de 1958, que, en su número o apartado 5, dispuso que los Gobiernos civiles y las oficinas de correos harán constar la hora y minuto de la presentación en el recibo que entreguen al interesado cuando éste así lo solicite. $Y$ así lo entiende también, claramente, según se acaba de ver, el precepto del R.D.P.M.E. que comentamos. En cambio, la Orden del Ministerio de la Gobernación de 20 de octubre de 1958 ha sido interpretada, erróneamente, en el sentido de reducir las formalidades a cumplir por los funcionarios de correos, a estampar el sello de fechas en la parte superior izquierda del documento principal (puesto que la instancia o escrito de que se trate puede ir acompañada de otros) y a cursar el mismo en forma idéntica a la que se sigue con los certificados en general. $\mathrm{Y}$ esta interpretación (por así llamarla, ya que el artículo $1.3 \mathrm{de}$ esta Orden es tan claro que no la necesita) es acertada; pero limitándola al tema del curso a dar a las instancias y escritos por los funcionarios de correos, que es al que se refiere su artículo 1, cuyo epígrafe reza: "Curso de instancias o escritos". Lo que no es posible, aunque se haya hecho, es extenderla al problema del recibo a entregar al interesado, que no resulta aludido en ninguna parte de tal Orden, por lo que las formalidades a cumplir por los funcionarios de correos, si el particular exige tal recibo, son las que se deducen del artículo 69.2 de la L.P. A. y del D. A. D. M. Y lo mismo puede decirse con respecto al artículo 205 del Reglamento de los Servicios de Correos, que se refiere sólo a la «admisión de instancias y escritos dirigidos a Centros o dependencias administrativas", proporcionando normas al respecto, sobre todo en cuanto a la fecha e, incluso, hora de presentación (26), pero silenciando, igualmente, el tema del recibo, cuya regulación sigue siendo la contenida en el tan repetido artículo 69.2.

Por muy correcto que sea lo anterior, ¿qué apoyo presta a su vigencia efectiva este artículo 52 del R.D.P.M. E.? Desgraciadamente, ninguno. En la introducción se dejó dicho que sus disposiciones sólo tienen eficacia intra muros del Ministerio y no pueden

(26) Lo que interesa a efectos del artículo 69.4, párrafo primero, de la L.P.A. y del D.A.D.M. y también del 74.2 de ambas disposiciones. 
oponerse, por tanto, a las normas, también de tipo interno (27), emanadas de las autoridades de Correos y que, aunque erróneas, han logrado eliminar la garantía que la expedición del recibo, en sus distintas modalidades, supone para el particular (28). En otro caso, no cabe duda de que este Reglamento hubiera forzado una solución al problema que nos ocupa ya que, siendo idénticos, respecto a estos extremos, la L. P. A. y el D. A. D. M., el mismo trato habría que dar a los escritos presentados en Correos y dirigidos al Ministerio del Ejército, que a los que se dirigieran, a través de idéntica vía, a la Administración civil del Estado. Lo paradójico sería que la solución correcta se hubiera impuesto por imperio de un Reglamento y no una Ley precedente (29).

En otro orden de cuestiones, cabe anotar, como acierto indudable del R. D.P.M. E., la disposición contenida en su artículo 55 , según el cual la totalidad de la correspondencia, excepto la de carácter secreto, será abierta en el Registro general del Ministerio. Ello implica la agilización de su funcionamiento al evitarse la demora que supondría la apertura de aquélla por un superior o en su presencia (30) y posibilita el que, en el mismo día de su recepción, puedan los escritos ser clasificados, anotados en el Registro general y remitidos al registro particular de la dependencia que corresponda ( $v i d$. artículos 50, 55.1 y 56 de este Reglamento), con lo que se da plena virtualidad a lo dispuesto en los artículos 65.4 de la L.P.A. y del D. A. D. M.

Lo anterior no se completa, sin embargo, con otros aciertos. Así, ni la L.P.A. ni el D.A.D.M. exigen que el Registro se lleve mediante libros al efecto. Con respecto a la primera de estas disposiciones, dice López-Nieto (31) que «no nos habla de libro de

(27) En cierta ocasión, hace ya algunos años, le fueron mostradas al autor de este trabajo, por el jefe o encargado de una oficina de correos, instrucciones de sus superiores tajantemente prohibitivas de fechar, firmar o sellar las copias que los particulares les presentaran para ello. En la actualidad, no me ha sido posible examinar de nuevo dichas instrucciones.

(28) Martí Mateo: Manual de Derecho Administrativo, Madrid, 1970, página 335, afirma que res lo cierto que en estos momentos, aunque normalmente los escritos llegan a su término con regularidad, no se puede tener total garantía de que el escrito presentado en Correos va a llegar a la oficina de su destino...n.

(29) MARTfN MATE0, obra citada, página 335, sugiere aun servicio de fotocopias organizado y garantizado por la propia Administraciónn, en determinadas unidades de Correos. ¿Y si las copias o fotocopias se presentaran en Correos ya compulsadas (por un notario, por el encargado del registro de los Ayuntamientos), a costa del particular, y con las debidas garantías, puestas por el mismo autenticador, en el papel del original y en el de la copia?

(30) Vid. el retrógrado artículo 271 del R. O.F.

(31) LOPEZ-NIETO: El procedimiento administrativo, Barcelona, 1960, página 250. 
registro, por lo que no hay inconveniente en admitir que pueden hacerse (los asientos) de otra forma. Modernamente se ha hablado de otros sistemas que pueden ser más cómodos y dar mejores resultados...». La doctrina ha propuesto (32) «un sistema de hojas intercambiables mecanográficas, en sustitución del libro de registro manuscrito que permite una mayor rapidez en su confección y facilita mejor el control de los documentosi. En el ámbito de la Administración local, pese al obstáculo que representan los artículos 264 y siguientes del R. O. F., que hablan expresamente de libros de entrada y libros de salida, se ha planteado (33), a través de un exhaustivo examen de la cuestión, la supresión del libro-registro por hojas sueltas - relaciones de entrada- que se encuadernarán diariamente, obteniéndose de estas relaciones tantas copias cuantas sean precisas para constituir los registros parciales de las Secciones, Negociados y Servicios y órganos de control. Las mismas posibilidades ofrece el D. A. D. M.; pero el R. D.P.M. E. las ha frustrado, pues su artículo 62.1, párrafo segundo, y 2, indica expresamente que los diferentes registros particulares se llevarán mediante libros, lo que implica también la utilización de libros en el Registro general. De ahí la necesidad de confeccionar los índices, a que aluden sus artículos 62 y 63, y otras previsiones innecesarias con todas las desventajas que ello comporta y con desaprovechamiento evidente de las favorables consecuencias que un sistema, como el apuntado de relaciones de entrada, produce en orden a la economía, celeridad y eficacia en la tramitación procedimental (34).

Por último, debe anotarse que el R.D.P.M.E. ha perdido una magnífica oportunidad de organizar el Registro General como una dependencia a tono con el amplio e importante cometido que, en orden al procedimiento administrativo, puede desempeñar, singularmente en lo relativo a la materia sobre la que versa el siguiente apartado, así como tampoco han sido atisbadas las ventajas derivadas de su posible incardinación en las llamadas Oficinas de Información (35). A mi modo de ver, hay una incongruencia manifiesta

(32) Naranjo, D., y Elices, A.: «Registro de documentos en las Iefaturas Provinciales de Tráficon, en $D$. A., número 96 , página 116.

(33) CaRrasco, VizcafNo y MaHfllo: Simplificación administrativa..., citado en nota (19).

(34) Vid. Carrasco, Vizcafo y Mahfllo: Simplificación administrativa..., cit. páginas $141 \mathrm{y}$ siguientes.

(35) VizcafNo, en explicaciones de los Cursos de Organización y Métodos, que viene impartiendo en la Escuela Nacional de Administración Local, y CaRRasco, VIZCAfNO y MAHfLL, en Simplificación administrativa..., cit. páginas 81-82, afirmaban 
entre las normas y propósitos de racionalización, mecanización, eficacia, etc., de la actuación administrativa y la organización y funcionamiento efectivos que la praxis presenta. Los principios en que se quiere inspirar la L.P.A. y, obviamente, el D.A.D.M., permitían mayores posibilidades funcionales al Registro General.

\section{EL PROCESO DEL TRABAJO ADMINISTRATIVO EN EL PROCEDIMIENTO}

Con encomiable propósito procura el R.D.P.M.E. ordenar la actividad administrativa dedicada al estudio y tramitación del procedimiento en las fases previas a su resolución. A tal efecto, su artículo 37 señala las siguientes etapas o fases a observar por los distintos negociados: «Estudio inicial del expediente para determinar su procedimiento"; "tramitación del expediente y petición de informes»; "estudio final del expediente». (36).

Ello obedece, repito, a una laudable finalidad de ordenación de tareas, que se ve potenciada por la coordinación que su artículo 6 trata de asegurar y que se destaca como novedad, aunque no lo sea tanto, en las palabras preliminares. Por otra parte, las previsiones sobre tiempos máximos de duración de algunas fases, la consignación de los plazos legales para el cumplimiento de los diversos trámites, etc. (vid. el citado artículo 37), muestra el interés del R.D.P.M. E. para asegurar el acierto al resolver y la previa rapidez en la tramitación, lo que, en unión de lo anterior, supone también un propósito simplificador que, a mi juicio, debió ser lisa y llanamente explicitado.

El estudio inicial del asunto puede, verosímilmente, quedar plasmado en un diagrama que represente gráficamente el proceso a seguir. Con ello, según destaca Vizcaíno Coloma (37), desaparece

que ase precisa, por tanto, transformar los cometidos del Registro, convirtiéndolo, en este aspecto, en Oficina de Información y de gestión en beneficio de los administrados». En las páginas 84 y siguientes enumeran y analizan las funciones posibles de información, suministro de impresos, confección gratuita de instancias, suministro de efectos timbrados y mutuales, recaudación de tasas por expedición de documentos, confección de relaciones de entrada y confección de fichas-guía, función esta última que será aludida en el apartado siguiente.

(36) Las frases entrecomilladas, recogidas del artículo 37 del R. D. P.M. E., demuestran la afirmación, contenida en las primeras líneas del apartado II de este trabajo, de que la indebida utilización del término expediente no autoriza a suponer confusión conceptual en quienes así proceden, pues está claro lo que se quiere indicar con ellas.

(37) Vizcafno Coloma: Apuntes tomados de sus explicaciones en el Curso de Organización y Métodos. 
la improvisación y la necesidad de ir dictando providencias de trámite impulsoras, al concretarse en el diagrama quién tiene que hacer cada operación, cuándo ha de hacerla, en qué tiempo, a quién habrá de dirigirse el expediente, así como el momento en que ha de adoptarse la decisión y por qué órgano. Ahora bien, ello puede y debe hacerse no sólo, como parece deducirse del artículo 37 que comentamos, a partir del momento en que los asuntos han sido distribuidos entre los negociados, sino, con referencia a muchos supuestos, en un momento anterior. Efectivamente, los procesos típicos deben ser objeto de un estudio previo para determinar su diagrama anticipadamente y así toda instancia o acuerdo iniciador de oficio encuentra precisada de antemano su tramitación. Sólo tratándose de procesos atípicos es necesario ese estudio inicial para fijar el procedimiento que quedará preestablecido como primera providencia de su trámite. Procediendo como queda indicado, la segunda fase de las reseñadas queda simplificada al máximo. En ella casi desaparece, como se deduce de lo anteriormente expresado, la necesidad de ordenación intermedia del trabajo, que quedará reducida a los escasos supuestos de aparición de datos anómalos, irregulares o nuevos. $Y$, de otro lado, el análisis minucioso y exacto del proceso a seguir permite concretar qué trámites admiten, por no estar subordinados entre sí, un trabajo simultáneo o en paralelo, frente al tradicional sistema del trabajo encadenado en secuencias (38).

La confección de estos diagramas es valiosa no sólo a efectos operativos de tramitación, sino también a los fines del control atribuido a los Jefes de Sección (artículo 29, d), del R.D.P.M. E.) y del que pueda corresponder a los funcionarios superiores y autoridades del Ministerio (39). Para ello bastará que los mismos se integren en las llamadas fichas-guía o fichas-índice, «que no son más que impresos de tamaño folio, en los cuales, tras de constar los datos generales del solicitante y del objeto de la petición, se indican todas las fases del proceso típico, con las columnas correspondientes para consignar la fecha de la operación o transporte y las ob-

(38) Vid. mi trabajo, para el Curso de Diplomados en Organización y Métodos: «Procedimiento administrativo ordinario para la producción de actos municipales en primer pronunciamiento. Determinación de su régimen jurídico y simplificación del mismon, página 130. (Hay un ejemplar en la Biblioteca del Instituto de Estudios de Administración Local).

(39) Los diagramas y las fichas-índice, a que se alude seguidamente en el texto, son también elementos utilísimos a efectos del deber de suministrar información. 
servaciones precisas» (40). A cada instancia o acuerdo que deba originar un expediente se abre una ficha-indice, obteniéndose de la misma las copias precisas para que un ejemplar vaya siempre unido al expediente, otro se envíe al negociado a que corresponda la tramitación y otro, u otros, al jefe de sección o demás órganos que ejerzan control. En el ejemplar unido al expediente se va consignando la realización de los trámites impresos en el diagrama, anotando la fecha y las observaciones precisas. Al final de cada jornada o período de tiempo se comunica a la sección o demás organismos de control el cumplimiento de los diversos trámites para que éstos actualicen sus fichas-índice. Como quiera que en el diagrama aparecen también reseñados los tiempos dentro de los cuales ha de realizarse cada trámite, el retraso es advertido inmediatamente y la subsanación procedente o las medidas que correspondan pueden adoptarse sin dilación alguna (41).

La última fase de las anteriormente enunciadas es «el estudio final del expediente, una vez reunidos los elementos de juicio necesarios para emitir el informe o propuesta de resolución». Esta implica la consideración completa de un problema, la culminación del trabajo asesor y se traduce en un proyecto de resolución (42). Es un tipo de trabajo intelectual, la bondad de cuya realización radica, en último extremo, en resortes personales y en medios jurídicos que estimulen o, si es preciso, coaccionen a tal trabajo eficazmente (43). Habida cuenta de su importancia, se concede por el R.D.P.M.E. (artículo $37, c$ ), un plazo máximo de quince días para su emisión, que estimamos algo excesivo para los supuestos más corrientes $u$ ordinarios que no planteen particular dificultad y suficiente aún en asuntos que ofrezcan cierta complicación. En los casos de especialísimas circunstancias de dificultad, el siguiente apartado $d$ ) de este artículo 37 citado permite la solicitud de un plazo mayor.

La alusión al tema de plazo que se acaba de hacer; hace oportuna la dedicación de unas líneas a este respecto. El estudio inicial del asunto para determinar su procedimiento ha de hacerse en un plazo máximo de cuatro días, según el apartado a) del artículo 37

(40) Carrasco, Vizcafono y Mahfllo: Simplificación..., cit. página 96.

(41) Las consideraciones del texto se hacen en base a los apuntes tomados a Vizcafno Coloma en sus ya aludidas explicaciones del Curso de Organización y Métodos. En la misma obra y página citada en la nota anterior, se dice que el mecanismo del control será aobjeto de una posterior publicaciónn, tarea a la que me permito alentar a Vizcaíno y demás autores por la utilidad de la misma.

(42) Vid. mi libro Iniciación..., cit. página 181.

(43) Vid. mi trabajo citado en nota (38), página 95. 
de referencia. Este plazo puede ser economizado, generalmente, si, como se ha dicho, sólo los procesos atípicos imponen la necesidad de este estudio. La tramitación subsiguiente no tiene señalado, justificadamente, plazo alguno para su realización; su duración dependerá de las actuaciones que la integren, si bien hay posibilidades de reducción derivadas de las consideraciones siguientes: El apartado $b$ ) de este artículo 37 dice que «se consignarán en las comunicaciones los plazos legales para el cumplimiento del trámite»; pero estas comunicaciones pueden ser obviadas, salvo casos muy especiales, por la determinación e impulsión a priori del procedimiento. Restan, pues, trámites que pueden ser cumplidos o bien simultáneamente, o bien en forma sucesiva, lo que implica un ahorro de tiempo en el primer caso, que no es posible en el segundo. $\mathrm{Y}$, por último, es de resaltar que, a tenor del artículo 41.3, párrafo segundo, del R.D.P.M. E., "de no recibirse el informe en el plazo señalado, podrán proseguirse las actuaciones sin perjuicio de la responsabilidad en que incurra el funcionario culpable de la demoran. Ello, aparte de otras consideraciones, implica una laudable medida encaminada a asegurar la no paralización del procedimiento, aunque tal efecto no será siempre posible, según se expondrá al tratar de los informes en el apartado siguiente.

Respecto al plazo de quince días para el estudio final, ya se ha anticipado el juicio que merece. Sólo resta añadir que la decisión de la autoridad para ampliarlo no es discrecional, puesto que sólo procede "en algún caso extraordinario», el cual podría postular no sólo la mencionada ampliación, sino también la reducción del plazo. Por ello parece más acertada la previsión contenida en el artículo 289.1 del R. O. F. que contempla expresamente ambas posibilidades (44).

Como conclusión final de los comentarios hechos en este apartado, creo que debe resaltarse la preocupación de los redactores del R.D.P.M.E. por la recta ordenación y tramitación del procedimiento, preocupación que resiste muy favorablemente la comparación con las disposiciones contenidas generalmente en normas semejantes, si bien, como he procurado resaltar, el sistema adop-

(44) El artículo 289.1 del R. O.F. dispone: «Los informes, dictámenes o propuestas habrán de emitirse en término de ocho días, que podrá ampliarse a otros ocho o reducirse a la mitad cuando, a juicio del Presidente, así lo aconseje la importancia o complejidad del caso o lo requieran los intereses de la Corporación. Destaca en este precepto no sólo la posibilidad de reducir motivadamente el plazo normal, sino la más ponderada fijación de éste en ocho días. 
tado es susceptible de mejoramiento (45). Y ello, de manera indefinida en el tiempo (46).

\section{INFORMES}

Dice el preámbulo del R.D.P.M. E. que, teniendo en cuenta su naturaleza reglamentaria, se evita la reproducción en el mismo del articulado de textos procedimentales precedentes «salvo en los casos en que la frecuente aplicación del precepto de que se trate, convierte en útil su transcripción en este Reglamento". En virtud de ello, su artículo 41 es reproducción casi enteramente literal de los artículos 84,85 y 86 de la L.P.A. y del D. A.D. M., que, por otra parte, no necesitan, dada su claridad y precisión, desarrollo ulterior (47), excepto en lo relativo a la posibilidad de prosecución de actuaciones en los supuestos de omisión de informes.

También obvia la naturaleza del texto que se comenta, toda disquisición sobre cuestiones tales como concepto, clases, valor de los informes, etc., que he examinado cumplidamente en otro lugar (48). Sí es posible, en cambio, insistir algo en lo relativo al proceso de producción de los informes y, por su importancia, en el tema de la omisión de los mismos.

A los jefes de negociado corresponde, según el artículo $30, b$ ), del R. D. P. M. E., «impulsar la tramitación de los asuntos pendientes de resolución definitiva», lo que se concreta en su artículo $37, b$ ), a cuyo tenor, una vez determinado el procedimiento, los negociados deben proceder a la "tramitación del expediente y petición de informes, en su caso", función esta última que el artículo $29, b$ ), in finem, señala como cometido específico de los jefes de sección, salvo que disposición expresa exija la mediación de autoridad determinada. Se produce así una cierta dificultad en esta materia, que, sin embargo, estimo superable.

La impulsión del procedimiento es función a ejercer, según lo

(45) Estudios sobre organización y procedimiento, en orden a mejorar el trabajo administrativo, son muy necesarios en todos los ámbitos. Un ejemplo a citar, muy esquemático, aunque sustancioso, es el de Vizcafno Coloma: «Mejora de métodos de trabajo en las Corporaciones locales", en Boletín de Información de la Vida Local, número 4, páginas 26 y 27.

(46) En mi estudio cit. en nota (38), páginas 119 y siguientes, apunto un sistema, sobre el que sería necesario meditar más, en el cual el trabajo actual en secuencias sucesivas sería excepcional.

(47) A pesar de lo que se dice en el texto, la Orden Circular del Ministerio de la Gobernación de 28 de octubre de 1958 y la Orden de la Presidencia del Gobierno de 31 de diciembre de 1958 contienen normas sobre los informes.

(48) NúNEZ MAROTO: Iniciación y desarrollo..., cit. páginas 124 y siguientes. 
expuesto en el apartado anterior, de modo previo, pues la tramitación procedente queda concretada en los diagramas establecidos a priori en los procesos típicos o en los resultantes del estudio inicial que ordena el artículo $37, a$ ), si se trata de procesos atípicos. Y la petición de los informes previstos en dichos diagramas la hacen y firman, en mi opinión, los jefes de negociado cuando se trata de informes a emitir en el propio ámbito interno del organismo de que se trate, dándose así plena virtualidad al artículo $37, b$ ); en cambio, si se trata de informes que deben emanar de otros organismos la petición debe hacerla y firmarla el jefe de la sección, salvo la excepción antes apuntada, por aplicación del artículo 29, b).

Ahora bien, una cosa es que sea el jefe de la sección o el del negociado quienes firmen el escrito de solicitud de informes y otra, muy distinta, que puedan o no acordar que tal solicitud se haga. Tratándose de informes preceptivos no se plantea tal problema, pues su necesidad es conocida de antemano y el informe estará ubicado adecuadamente en el flujo de trabajo descrito en el correspondiente diagrama, por lo que, en el momento procedimental oportuno, se procederá, sin necesidad de acuerdo expreso, según corresponda a tenor del criterio expuesto anteriormente. Si se trata de informes facultativos, éstos pueden haber sido previstos igualmente en el estudio previo o inicial del que resulta la concreción del procedimiento a seguir, en cuyo supuesto tampoco se plantea problema, debiendo procederse de la misma manera indicada. Pero también puede posteriormente aparecer la necesidad de informes facultativos que, por tanto, no están previstos en el diagrama. Ello ocurrirá:

- Por contingencias surgidas durante la tramitación, que reclamen la dirección intermedia del procedimiento.

- Si, terminada la instrucción en todos los trámites inmediatamente anteriores a la propuesta, el jefe de negociado, en vez de formular aquélla, expresa la necesidad o conveniencia de solicitud de informe facultativo (arg. artículos 37, c) y 38).

- Si los jefes de sección, tras estudiar los asuntos que les presenten los negociados, no confirman la propuesta de éstos o no formulan otra, sino que manifiestan igualmente la conveniencia o necesidad de informe facultativo (arg. artículo 39).

- Si la autoridad competente así lo decide (arg. artículo 39).

En todos estos supuestos, el acuerdo de solicitud de informe facultativo ha de emanar, obviamente, de la autoridad que tenga 
competencia para resolver, bien como propia, bien en virtud de delegación o desconcentración, como es el caso de los directores (vid. artículos $28, a$ ) y 40). Dictado dicho acuerdo, el informe lo firmarán el jefe de negociado o el de sección, según la regla general apuntada.

En cuanto al otro problema objeto de consideración en este apartado, esto es, el de la posibilidad o no de continuar la tramitación, caso de no recibirse el informe en el plazo oportuno, el segundo párrafo del número 3 del artículo 41 del R.D.P.M.E. lo soluciona igual, es decir, con la misma imprecisión originadora de dificultad interpretativa, que el artículo 86.3 de la L.P. A. y D. A.D. M.: «De no recibirse el informe podrán proseguirse las actuaciones sin perjuicio de la responsabilidad en que incurra el funcionario culpable de la demora».

El precepto transcrito da pie a varios comentarios. En primer lugar, cabe que el informe haya sido solicitado y no emitido en el plazo correspondiente, pero sí con posterioridad. A mi parecer, éste es el supuesto que encaja típicamente en el aludido precepto: se trata de informes emitidos fuera del plazo legal, informes tardíos, que no paralizan, en modo alguno, las actuaciones y que sólo originan la responsabilidad disciplinaria del funcionario a quien sea imputable lal tardanza. Si los informes preceptivos implican, por definición, un trámite legalmente imprescindible y los facultativos han de limitarse a «los que se juzguen absolutamente necesarios para acordar o resolver... fundamentando... la conveniencia de reclamarlos» (artículos 41.1 del R. D. P. M. E. y 84.1 de la L.P. A. y D. A.D.M.), es evidente que la disciplina legal y reglamentaria de este trámite concreto del informe parte del supuesto de su emisión, aunque sea con retraso. Lo que la Ley ha querido es que las actuaciones puedan proseguir sin peligro para la validez del acto.

$\mathrm{Si}$, en otro caso, el informe no se emite, bien porque no ha sido solicitado, bien porque, a pesar de haberlo sido, la correspondiente solicitud $u$ orden no es atendida, conviene distinguir atendiendo a su carácter facultativo o preceptivo. La omisión de informes facultativos no paraliza las actuaciones porque, al estar contemplados en la Ley como mera posibilidad en cuanto a su petición, no tiene relevancia suficiente para producir la anulabilidad del acto final o resolutorio. La omisión de informes preceptivos, por el contrario, debe producir la paralización del procedimiento puesto que están previstos como trámites necesarios para ilustrar la inteligencia del 
órgano llamado a dictar resolución. Ya la Orden Circular de 28 de octubre de 1958 expresaba, aunque sin la debida rotundidad, que la posibilidad de proseguir las actuaciones, caso de no recibirse los informes en el plazo señalado, hay que entenderla referida para aquellos supuestos en que no sean preceptivos, pues, de serlo, «no parece posible (el subrayado es mío) proseguir el procedimiento sin aquéllos» (número 22, párrafo anteúltimo, de la Orden Circular citada). Sin vacilación alguna debe afirmarse que la resolución producida con omisión previa de un informe preceptivo es anulable puesto que ni siquiera cabe, respecto de ella, la convalidación posterior por expresa previsión del artículo 53.5 de la L.P.A. y del D.A.D.M. Por ello, la tramitación se paralizará si tal informe no se produce.

Ahora bien, lo anterior constituye el tratamiento normal de la materia; normal y, generalmente, correcto a tenor de los razonamientos expuestos. Pero recuérdese que los informes facultativos han de limitarse a «los que se juzguen absolutamente necesarios para acordar o resolver» (el subrayado es mío). La omisión de un informe facultativo, que haya sido solicitado y responda a tal grado de necesidad, puede privar al órgano decisor de un esencial elemento de juicio a la hora de dictar resolución; en consecuencia, si ésta se produjera sin tal informe debería ser anulada (49). De otra parte, ocurre que, a veces, aunque sean las menos, se configura como preceptivo un informe que no tiene $\tan$ decisiva influencia o cuyo efecto ilustrativo puede lograrse por otros medios (50). Creo que cabe postular que, en este último supuesto, debería poder proseguir la tramitación sin peligro para la validez del acto final, aunque el informe no se emita.

Estas últimas consideraciones pueden sugerir un cierto cambio legal y jurisprudencial en el tratamiento de la materia, ajeno a las actuales normas que integran el R.D.P.M. E.; pero, al menos, bien pudo éste incluir un precepto semejante, aunque más perfeccionado, al párrafo, anteriormente aludido, del número 22 de la Orden Circular de 22 de octubre de 1958.

(49) Creo necesario insistir en que no se trata de enjuiciar si se debió o no solicitar el informe facultativo, sino de las consecuencias que, en orden a la anulabilidad de la resolución, puede tener la omisión de tal informe, cuando haya sido solicitado por ser absolutamente necesario.

(50) El Derecho local nos proporciona un claro ejemplo de informes preceptivos no esenciales: Los que debe" emitir las llamadas Comisiones Informativas. Vid. mi libro Iniciación..., cit. páginas 141 y 147. 
REVL-1975, núm. 187. NUÑEZ MAROTO, HERMINIO. EL REGLAMENTO DE DESPACHO Y PROCEDI...

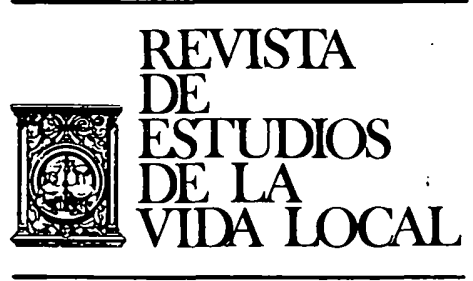

III. ESTADISTICA 
REVL-1975, núm. 187. NUÑEZ MAROTO, HERMINIO. EL REGLAMENTO DE DESPACHO Y PROCEDI... REVL-1975, núm. 187. NUÑEZ MAROTO, HERMINIO. EL REGLAMENTO DE DESPACHO Y PROCEDI... 